\title{
Islet encapsulation: advances and obstacles
}

\author{
G. C. Weir
}

Received: 3 April 2013 /Accepted: 4 April 2013 /Published online: 30 April 2013

(C) Springer-Verlag Berlin Heidelberg 2013

\begin{abstract}
It has been known for decades that encapsulation can protect transplanted islets from immune destruction in rodents, but it has proved difficult to extend this success to large animals and humans. A new study in this issue by JacobsTulleneers-Thevissen et al (doi: 10.1007/s00125-013-2906-0) advances the field by showing that human islets contained in alginate capsules can function very well, not only in the peritoneal cavity of mice, but also in a human with type 1 diabetes. Many obstacles must still be overcome, but this technology has the potential to safely protect transplanted beta cells from autoimmunity and allorejection.
\end{abstract}

Keywords Beta cell $\cdot$ Biomaterials $\cdot$ Diabetes ·

Encapsulation $\cdot$ Insulin secretion $\cdot$ Islets

\section{Abbreviation \\ IEQ Islet equivalent}

The paper by Jacobs-Tulleneers-Thevissen and co-workers in this issue [1] presents an advance in the re-energised field of islet encapsulation, which is a strategy to protect transplanted beta cells from immune destruction. The demonstration in 1989 [2] that the diabetic state can be reversed in humans by cellular transplantation provided an important proof-ofprinciple demonstration reinforcing the concept that the goal of beta cell replacement is a major priority for diabetes research. This potential is most obvious for type 1 diabetes, where even partial replenishment of near complete beta cell

\section{G. C. Weir $(\bowtie)$}

Section on Islet Cell Biology and Regenerative Medicine, Joslin Diabetes Center, One Joslin Place,

Boston, MA 02215, USA

e-mail: gordon.weir@joslin.harvard.edu

G. C. Weir

Department of Medicine, Harvard Medical School,

Boston, MA, USA deficiency with isolated islets transplanted into the liver via the portal vein can normalise blood glucose levels. Similar treatment approaches for type 2 diabetes are less often considered, but beta cell mass is generally reduced by $40-60 \%$ [3], and normoglycaemia can be restored with whole pancreas transplantation providing beta cell replacement [4].

The simplicity of the concept of beta cell replacement has created high expectations, but decades of intense work have been hindered by two obstacles: (1) the lack of an adequate supply of islet cells and (2) the absence of a means of protecting them from destruction by autoimmunity and allorejection. The quest to find a new source of beta cells has brought about impressive advances in unlocking the potential of stem cells and finding ways to exploit the possibility of islet cell regeneration.

Finding strategies to curb immune destruction has proved to be particularly daunting. The loss of tolerance in autoimmunity and the components of allorejection are now certainly better understood, but they are vicious complex processes that have proved difficult to control. Something better than the blunt instrument of current immunosuppression is needed. The frustration of not being able to identify a safe way to tame the immune system has sparked renewed interest in providing protection by encapsulation.

\section{Why work on encapsulation?}

The possibility that semi-permeable membranes can protect islet cells has attracted attention since the 1970 s, yet a great deal of work by a variety of academic scientists and industry has only resulted in variable success in rodents and little that is encouraging in large animals and humans [5]. The principle is that the islet cells are encapsulated using a membrane porous enough to allow passage of glucose, oxygen, nutrients and insulin, but restrictive enough to keep out immune cells and some potentially toxic cytokines, antibodies 
and complement proteins. The two main approaches are macro- and microencapsulation. Most macrodevices are flat thin rectangular containers made of various materials that can contain large numbers of islets. These might be implanted in subcutaneous or intra-abdominal sites, or even under the kidney capsule. Microcapsules typically contain just a few islets worth of cells within a hydrogel bead, most commonly consisting of alginate obtained from seaweed [6, 7]. Islets can also be individually covered with a tight-fitting conformal coating, typically consisting of polyethylene glycol (PEG) [8].

\section{Recent progress in islet encapsulation: advances and clarification of problems}

Advances The study by Jacobs-Tulleneers-Thevissen and co-workers in this issue [1] advances the field of islet encapsulation with two main findings. The first is that transplanted encapsulated human islet cells contained in alginate microcapsules placed in the peritoneal cavity can survive and reverse diabetes very well in mice, considerably better than comparable 'free implants' (non-encapsulated cells) transplanted under the kidney capsule. Following retrieval from the peritoneal cavity after 5 weeks, the beta cells in the capsules were found to have healthy insulin secretory responses to both glucose and glucagon stimulation, and their unique secretory granules could be identified by electron microscopy. Interestingly, the cell composition of cells in the capsules changed over the 5-week period. When initially encapsulated the population contained a lot of duct cells, as is typical for a human islet preparation ( $42 \%$ beta cells, $12 \%$ alpha cells and $41 \%$ duct cells), but after 5 weeks the proportion of duct cells was considerably diminished $(54 \%$ beta cells, $18 \%$ alpha cells and $20 \%$ duct cells). The explanation for this changed ratio is unclear, but probably results from differing rates of birth and death between islet and duct cells. Another intriguing possibility is that some duct cells differentiated into islet cells through the process of neogenesis [9]. These results suggest that microencapsulated human islets cells should also do well when transplanted into humans.

The second major finding resulted from placing microencapsulated human islets into the peritoneal cavity of an individual with type 1 diabetes, who had a failed intraportal islet graft but was still on immunosuppressive therapy. The islet dose was subtherapeutic and had no measurable metabolic impact, but it allowed the first detailed look at isletcontaining alginate microcapsules retrieved 3 months after transplantation in humans. The most encouraging findings were that some of the capsules were free floating without fibrosis and contained healthy beta cells that showed insulin secretory responses to stimulation by glucose, but, for unclear reasons, not by glucagon. Other good news is that the patient reported no abdominal discomfort or other symptoms following the transplant; this was also the case in two other reports of humans with transplanted encapsulated human islets [10, 11]. Taken together, these findings in mice and the pilot study with a human participant show that microencapsulated human islet cells can do well when transplanted into the peritoneal cavity.

Clarification of problems These studies also highlight some of the serious problems facing the field. Microcapsules containing islet cells and even 'empty capsules' without any cells can elicit an inflammatory reaction that covers the capsule surface and evolves to fibrosis. Islets inside fare badly, presumably mainly because of suffocation as a result of competition for oxygen from the inflammatory cells. These reactions are poorly understood but are likely to be due to some combination of reactivity of the biomaterials, the genetic background of the recipients, and the immune reaction to antigens and cytokines released by the contained cells. Xenografts do worse than allografts, and unhealthy cells are also more likely to have poor outcomes. An important consideration is that the immunosuppression provided for the patient in this study could have suppressed a reaction to the capsule.

Clumping of capsules in the peritoneal space is a major concern, which brings up the major issue of oxygen supply. It must be remembered that islets in capsules depend on oxygen diffusion from the bathing peritoneal fluid, the partial pressure of which is in the range of $45 \mathrm{mmHg}$ [12]. Competition for oxygen by nearby transplanted islets and/or by an inflammatory reaction on the capsular surface can cause hypoxia, with a resulting loss of function and even death. The clumps found in the present human study provide a worrisome lesson: the encapsulated islets in the centre of a clump must be starved for oxygen. The reduction of viable tissue in the centre of a clump is demonstrated in Fig. 3b of the paper of JacobsTulleneers-Thevissen et al, and is depicted as a diagram in Fig. 1 of this commentary. There have long been concerns that capsules will fall onto the pelvic floor of bipeds, thus forming clumps, with their inherent problems, and in the present study clumping was found not only on the pelvic floor but also in the greater omentum. New strategies must be developed to limit this clumping problem.

\section{Immediate challenges}

The islet cells of the future Human islet preparations come from cadaver pancreases and are therefore in short supply; they also typically contain many dead and dying cells and are contaminated with exocrine cells. They help advance research, but the prospect of using islet cells generated from pluripotent stem cells or other islet precursors in the future seems more promising $[13,14]$. Porcine islet cells could also suffice before an abundant human source is identified. An 


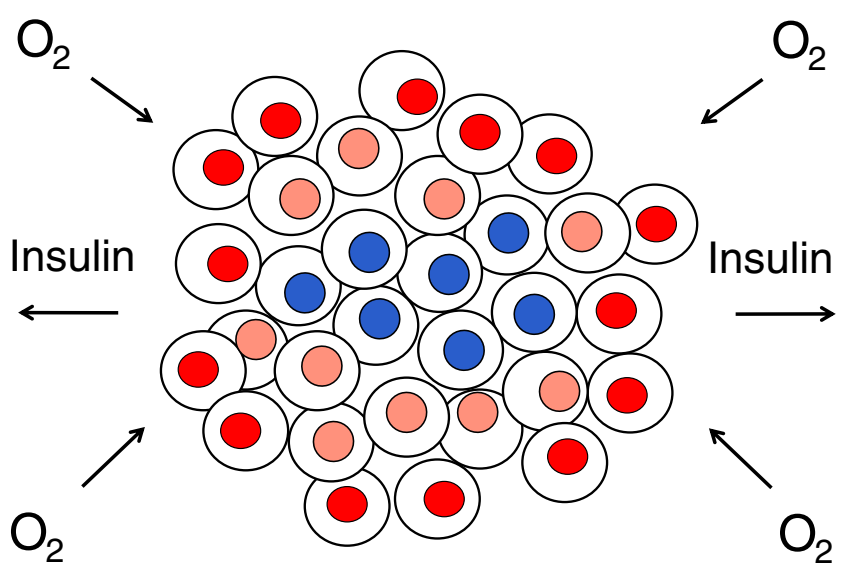

Oxygenated $\bigcirc$ Hypoxic $\bigcirc$ Dead

Fig. 1 The illustration depicts the importance of oxygen availability for the survival of encapsulated islets and highlights how clumping of capsules in the peritoneal cavity or elsewhere can lead to anoxic death of islets and altered insulin release kinetics. Only the islet cells on the outside of the clump will be well oxygenated. Moreover, insulin secreted from beta cells must diffuse a relatively long distance through a fluid space to reach a blood vessel, which will slow the delivery of insulin to key target sites such as liver and muscle. In a similar manner, after insulin secretion has been shut off by falling glucose levels, insulin will continue to diffuse out of the islet clumps for a significant period of time. The diffusion of glucose is much faster than the much larger insulin

interesting unanswered question is whether beta cells alone could provide adequate secretion or whether they must be accompanied by islet non-beta cells. Also, theory and some experimental data suggest that small aggregates of healthy islet cells with a diameter of 30-60 $\mu \mathrm{m}$ will function better than those that are islet-sized with a diameter of more than $150 \mu \mathrm{m}$ [15]. Another unresolved question is how long encapsulated human islet cells can survive and function in a transplant site. There is some evidence that they can survive for many months and even years [6, 16], but practical questions remain about the survival kinetics of islet cells and how often they will need to be replenished.

The need for more reliable biomaterials The most widely used material for microencapsulation is the hydrogel alginate, of which there are a variety of types, and cross-linking to form a gel can be provided by several cations. The gel bead can be coated with a polycation such as poly-L-lysine to add strength and provide more permselectivity. In addition, there are a variety of capsule sizes and configurations, including double core/shell versions. However, a major shortcoming of the field is that there are as yet no standardised formulations that can provide reproducible results in different laboratories.

How much permselectivity is required? While it is clear that immune cells must be separated from the islet cells, questions can be raised about the need to keep out cytokines, antibodies and complement proteins, or to limit the release of antigens. We know that high concentrations of cytokines can kill islet cells, but it has never been shown that these toxic levels are ever reached within capsules. There is some evidence in rodents that encapsulated xenogeneic tissue is more vulnerable than allogenic tissue and it is generally thought that tighter membranes provide better survival. Although it is logical to assume that release of xenoantigens is the culprit, we have little understanding of even which antigens are responsible.

Will the kinetics of insulin release be adequate? Secreted insulin from richly vascularised islets in the pancreas is rapidly delivered to blood such that insulin levels can rise quickly and fall in a just few minutes when secretion is shut off by declining glucose levels. Very little is known about the kinetics of insulin release from encapsulated islets, but because insulin must diffuse various distances before reaching the circulation, there may be problems obtaining timely release for meals and shutting insulin off after meals or during exercise. As depicted in Fig. 1, insulin release kinetics will be even more problematic when microcapsules are clumped.

The packing density issue This question focuses on oxygen supply and how much biomaterial is required to protect a given mass of islet cells. This becomes a major concern for current plans to transplant macroencapsulated islet precursor cells derived from pluripotent stem cells, which can develop into fully mature beta cells in an in vivo environment [13]. Preparations are underway to carry out human trials using planar macrodevices modelled after the much-studied TheraCyte device [17], with the expectation that the membrane will protect the cells from the immune system and contain potentially dangerous cells, such as those capable of forming teratomas. Because of potential dangers, the macrodevices should be easily retrievable, which makes the subcutaneous site the most obvious possibility.

How much islet tissue can be supported by a given surface area that receives oxygen from the vasculature of surrounding tissue? Experience suggests that there will only be enough oxygen to support about 1,000 islet equivalent (IEQ) $/ \mathrm{cm}^{2}$, with an IEQ defined as a standardised islet with a diameter of $150 \mu \mathrm{m}$ [18]. If a recipient requires 200,000 IEQ, then $400 \mathrm{~cm}^{2}$ of surface would be required, which would mean a sheet of $20 \times 20 \mathrm{~cm}$. This might be achieved with several smaller devices, but finding a surgical site to accommodate such a surface area will prove challenging. The situation could be improved if ways can be found to provide more oxygen by better vascularisation or other oxygen delivery approaches. This is less of a problem for microcapsules in the peritoneal cavity, but should remain a concern, particularly when capsules are large (diameter of $1,000 \mu \mathrm{m}$ or more). 


\section{Summary}

The concept that transplanted islet cells can be protected from immune destruction by a biomaterial barrier remains an attractive therapeutic approach in spite of the challenges being faced. In spite of these difficulties, the fact that this could lead to a major therapeutic advance, that many are now working on the problem, that progress is occurring, and that new concepts continue to emerge, justifies the renewed interest and support for intense investigation into the potential of this technology.

Duality of interest The author holds stock options of the company Beta-O2 Technologies Limited.

Contribution statement The author conceived, drafted, wrote and approved this commentary.

\section{References}

1. Jacobs-Tulleneers-Thevissen D, Chintinne M, Ling Z et al (2013) Sustained function of alginate-encapsulated human islet cell implants in the peritoneal cavity of mice leading to a pilot study in a type 1 diabetic patient. Diabetologia. doi:10.1007/s00125-013-2906-0

2. Scharp DW, Lacy PE, Santiago JV et al (1991) Results of our first nine intra portal islet allografts in type 1 , insulin dependent diabetic patients. Transplantation 51:76-85

3. Butler AE, Janson J, Bonner-Weir S, Ritzel R, Rizza RA, Butler PC (2003) Beta-cell deficit and increased beta-cell apoptosis in humans with type 2 diabetes. Diabetes 52:102-110

4. Nath DS, Gruessner AC, Kandaswamy R, Gruessner RW, Sutherland DE, Humar A (2005) Outcomes of pancreas transplants for patients with type 2 diabetes mellitus. Clin Transplant 19:792-797

5. O'Sullivan ES, Vegas A, Anderson DG, Weir GC (2011) Islets transplanted in immunoisolation devices: a review of the progress and the challenges that remain. Endocr Rev 32:827-844
6. Qi M, Morch Y, Lacik I et al (2012) Survival of human islets in microbeads containing high guluronic acid alginate crosslinked with $\mathrm{Ca}^{2+}$ and $\mathrm{Ba}^{2+}$. Xenotransplantation 19:355-364

7. de Vos P, Bucko M, Gemeiner P et al (2009) Multiscale requirements for bioencapsulation in medicine and biotechnology. Biomaterials 30:2559-2570

8. Cruise GM, Hegre OD, Lamberti FV et al (1999) In vitro and in vivo performance of porcine islets encapsulated in interfacially photopolymerized poly(ethylene glycol) diacrylate membranes. Cell Transplant 8:293-306

9. Bonner-Weir S, Li WC, Ouziel-Yahalom L, Guo L, Weir GC, Sharma A (2010) Beta-cell growth and regeneration: replication is only part of the story. Diabetes 59:2340-2348

10. Tuch BE, Keogh GW, Williams LJ et al (2009) Safety and viability of microencapsulated human islets transplanted into diabetic humans. Diabetes Care 32:1887-1889

11. Calafiore R, Basta G, Luca G et al (2006) Microencapsulated pancreatic islet allografts into nonimmunosuppressed patients with type 1 diabetes: first two cases. Diabetes Care 29:137-138

12. Goh F, Sambanis A (2011) In vivo noninvasive monitoring of dissolved oxygen concentration within an implanted tissueengineered pancreatic construct. Tissue Eng Part C Methods 17:887-894

13. Schulz TC, Young HY, Agulnick AD et al (2012) A scalable system for production of functional pancreatic progenitors from human embryonic stem cells. PLoS One 7:e37004

14. Rezania A, Bruin JE, Riedel MJ et al (2012) Maturation of human embryonic stem cell-derived pancreatic progenitors into functional islets capable of treating pre-existing diabetes in mice. Diabetes 61:2016-2029

15. O'Sullivan ES, Johnson AS, Omer A et al (2010) Rat islet cell aggregates are superior to islets for transplantation in microcapsules. Diabetologia 53:937-945

16. Elliott RB, Escobar L, Tan PL, Muzina M, Zwain S, Buchanan C (2007) Live encapsulated porcine islets from a type 1 diabetic patient $9.5 \mathrm{yr}$ after xenotransplantation. Xenotransplantation 14:157-161

17. Lee SH, Hao E, Savinov AY, Geron I, Strongin AY, Itkin-Ansari P (2009) Human beta-cell precursors mature into functional insulinproducing cells in an immunoisolation device: implications for diabetes cell therapies. Transplantation 87:983-991

18. Barkai U, Weir GC, Colton CK et al (2012) Enhanced oxygen supply improves islet viability in a new bioartificial pancreas. Cell Transplant. doi:10.3727/096368912X657341 